\title{
LA CANCIÓN DE LOPE DE VEGA MURMURABAN AL POETA (1605-1634). VERSIONES Y VARIANTES
}

\author{
Macarena Cuiñas Gómez \\ Universidad de Vigo
}

Uno de los cometidos de la filología clásica, probablemente el más importante, se circunscribe al ámbito de la tradición textual: aquel que fija su atención en las distintas versiones existentes de un texto literario modificadas por su autor a lo largo de un cierto período de tiempo. La reescritura de la forma y del contenido responde al deseo del poeta situado en su propio contexto sentimental, social, religioso o histórico. Este artículo se va a centrar en un caso muy concreto de reelaboración poética: el de la canción de Lope de Vega titulada "Murmuraban al poeta la parte donde amaba por los versos que hacía" incluida por este en las Rimas humanas y divinas del licenciado Tomé de Burguillos (1634). ${ }^{1}$ En ella Burguillos, seudónimo de Lope, incide en el amor no

1 Este trabajo completa el publicado en las Actas del VIII Congreso de la AISO, celebrado en la Universidade de Santiago de Compostela en julio de 2008, con el título «Estudio comparativo entre versiones lopescas de poemas incluidos en el Burguillos», Compostella Aurea, Santiago de Compostela: Publicacións, 2011, pp. 229-238. 
correspondido que siente por Juana, destinataria de varios poemas de este volumen, la cual le devuelve un desdén rayano en la crueldad. La canción conserva otra versión anterior del propio Lope publicada en la Primera parte de las flores de poetas ilustres de Pedro Espinosa en 1605..$^{2}$ Esta se desarrolla a lo largo de 147 versos repartidos en 12 estancias. En su extensión radica la primera gran diferencia, puesto que la forma definitiva incluida en el Burguillos se compone de 264 versos en 21 estancias. En su reescritura, Lope amplía la canción en nueve estancias más, mientras que rehace otras. ${ }^{3}$

El volumen en el que se incluye la primera versión de este poema, las Flores (1605) de Espinosa, constituyó la antología más importante del momento en España. En palabras de Pablo Jauralde "era una antología "de vanguardia", un producto para las minorías. ». ${ }^{4}$ En ella su autor escogió textos de los mejores poetas: Quevedo, Góngora, Lupercio Leonardo de Argensola, una amplia selección de poetas andaluces, antequeranos, etc. Y entre todos destaca Lope de Vega por el número de composiciones con las que se le representa: ocho en total. En este momento Lope era ya un renombrado autor de comedias cuyo éxito popular era incuestionable, además de haber publicado entonces obras como La hermosura de Angélica (1588), La Arcadia (1594), La Dragontea (1598) y las Rimas (1602). Estos poemas reproducidos en las Flores responden a formas italianistas, fundamentalmente sonetos, un sexteto-lira y una canción. ${ }^{5} \mathrm{Y}$ las distintas canciones incluidas en este volumen antológico desarrollan una temática diversa: satírica, amorosa, o religiosa.

Tras veintinueve años, Lope presenta al público una nueva versión de esta canción impresa en las Rimas de Tomé de Burguillos (1634). El inicio ya resulta significativo por lo que tiene de referente en la biografía lopesca, en la divulgación de sus amores juveniles con Elena Osorio, asunto que tantos problemas le acarreó. Parece que a estas alturas de su vida, más reposado, pretende cambiar de estilo y abandonar las bravatas de joven enamorado por la expresión del sentimiento de un hombre maduro y más culto, aunque continúe valiéndose de la parodia, como veremos. Así comenzaba la canción en las Flores $^{6}$ :

$$
\begin{aligned}
& \text { Pves que ya de mis versos y passiones } \\
& \text { todo el mundo presume, } \\
& \text { y no ay necio que pierda su alcaldada, } \\
& \text { quiero mudar de estilo y de razones, }
\end{aligned}
$$

\footnotetext{
2 Ambas versiones se encuentran reproducidas en el Apéndice 1.

3 Todas las variantes se encuentran recogidas en el Apéndice 2.

4 Prólogo al libro de Pablo Villar Amador, Estudio de «Las Flores de poetas ilustres de España» de Pedro de Espinosa, Granada, Universidad de Granada, 1994, p. 11.

5 Ibidem.

6 Cito por la edición de las Flores de Inoria Pepe Sarno y José María Reyes Cano, Madrid, Cátedra, 2006, pp. 443-448.
} 
y así en el Burguillos:

Ya pues que todo el mundo mis pasiones

de mis versos presume,

culpa de mis hipérboles causada,

quiero mudar de estilo y de razones

En ambas versiones pretende corregir su estilo porque es consciente de su fama de amante indiscreto, pero mientras en la primera versión escrita con anterioridad a 1605 culpa a los demás («y no hay necio que pierda su alcaldada»), en la segunda se muestra humilde y se acepta como el único responsable de sus actos («culpa de mis hipérboles causada»). Este rasgo de madurez distingue una composición de otra ya desde su inicio.

Antes de concluir la primera estancia existe otra diferencia entre los cuatro últimos versos. La primera versión de las Flores decía así refiriéndose a las musas que habitan el monte Parnaso, a las que llama «rubia manada»:

Prestáme vuestra ayuda o melecina,

para que el vulgachón que me adeuina

no entienda los concetos

que entre vuestras albardas van secretos.

Y en el Burguillos:

prestadme vuestra ayuda sobre prenda

para que el vulgo bárbaro no entienda

por mis necios efectos

el alma de mis versos y concetos.

Mientras en uno el poeta es despectivo con el público al que llama «vulgachón», en el otro, lo denomina «vulgo bárbaro», calificativo más respetuoso, y achaca a sus «necios efectos» la culpa de que estos descubran el significado de sus versos, carentes de velo poético, cuyos referentes reales parecen ser muy evidentes para el lector o espectador de la época.

Muchas son las diferencias de estilo de tipo léxico, metafórico, etc., como el inicio de la segunda estancia que en la primera versión dice «Que si escriuiendo en socarrón estilo,» y en la segunda «Que si animando tan humilde estilo,». La sustitución del verbo figurativo «escribir» por el metafórico «animar», construye un segundo plano de significación poética en la que el vate se muestra como el creador de las palabras. Por otro lado, al adjetivar su estilo como «humilde» frente a «socarrón», lo liga a la clasificación clásica-culta alejándolo de la vulgaridad.

\footnotetext{
7 Cito por la edición de las Rimas humanas y divinas del licenciado Tomé de Burguillos de Macarena Cuiñas Gómez, Madrid, Cátedra, 2008, pp. 427-438.
} 
Unos versos más abajo, los 19-20, son transformados con el fin de lograr un matiz culto en la metáfora expresada con la introducción del elemento mitológico. Así en la primera versión decía «en los bordados reinos del Aurora, / donde el árabe mora,» y en la definitiva, «y en los bordados reinos del Aurora, / que Febo infante dora,».

La tercera estancia narra una conocida anécdota del Madrid de la época en la que los vecinos del Manzanares asaetearon unos odres de vino que bajaban por el río confundiéndolos con una ballena. ${ }^{8}$ Así, el agua del río teñida por el vino construía la siguiente imagen poética en la primera versión: «haziendo turbia la raudal corriente»; y esta en la segunda: «oscureciendo su cristal corriente». De nuevo se sustituye una descripción realista, el agua se ha vuelto turbia al mezclarse el vino con ella, por una metáfora: el agua, ahora «cristal», se oscurece por causa del vino. El significado no varía, aunque sí la expresión.

En la misma línea se observan referencias populares de corte romanceril en la primera versión, que se eliminan en la segunda en aras de un estilo más elaborado. Así los versos 41 y 44 de la estancia cuarta que decía: «En este vn Martes, pardo, haziago y malo, / Para bodas y telas,» frente a «En éste, un martes pardo, aciago y malo / para casar doncellas,»; y describe la belleza de Juana con «Aquellos ojos como dos candelas,» frente a «y aquellos ojos como dos estrellas,».

El remate de la estancia también varía, y la referencia del último verso en la primera versión: «Mase Cupido disparó vna flecha,», se convierte en la segunda en una estancia completa, nueva, que abarca los versos 53 al 65, cargada de erudición mitológica parodiada, uno de los rasgos de las Rimas de Tomé de Burguillos. Dice así:

Mas si Cupido, entonces lisonjero,
en vez de la sangrienta
ballesta de sangrar rocines y hacas,
tiróme con la mano de un mortero,
que, durmiendo una noche en una venta,
hurtó para tirar a las urracas;
tal en indias hamacas
suele desvanecerse, o en la nave,
quien ni del mar ni del columpio sabe,
quedando yo tan triste y descompuesto
como después de las vendimias cesto,
dando más estornudos
que los tabacos dan por los embudos.

8 Por este suceso, los habitantes de las riberas del Manzanares fueron llamados ballenatos. De esta anécdota se hace eco Lope en El galán escarmentado (acto I) y La noche de San Juan, así como otros poetas de su tiempo, Tirso de Molina, Quevedo o Alonso de Castillo Solórzano que relata el caso con pormenor en sus Jornadas alegres (Vid. José Fradejas Lebrero, Geografía literaria de la provincia de Madrid, Madrid, Instituto de estudios madrileños, CSIC, 1992 (1ª ed. 1958), pp. 72-78). 
Vemos que Cupido no le ha disparado una flecha sino «la mano de un mortero», así el amor le ha producido tal descalabro interior que se compara al cesto tras la vendimia y a un estado catarral peor que el provocado por el tabaco. Sin duda la parodia es brutal.

La estancia 5 de la versión original se convierte, por lo tanto, en la número 6 para la definitiva. En ella compara el sol entrando por las rendijas del tejado, con el amor por ella que se ha colado en su alma. La dama, que entró a su «helado pecho»y, para la primera versión,

$$
\begin{aligned}
& \text { que alli me lo dexó ceniza hecho } \\
& \text { tanto que el humo espeso que salia } \\
& \text { de horno de ladrillo parecia: } \\
& \text { Si alguno me encontraua, } \\
& \text { del tufo de mi mal estornudaua. }
\end{aligned}
$$

Y para Burguillos:

$$
\begin{aligned}
& \text { suave ardor de mis sentidos hecho, } \\
& \text { aunque el fuego que el humo interrumpía } \\
& \text { en densa nube el aire convertía. } \\
& \text { Si alguno me miraba } \\
& \text { del tufo de mi mal estornudaba. }
\end{aligned}
$$

Aunque ambas versiones mantienen el mismo final burlesco, sin duda existen grandes diferencias entre ellas. La primera emplea un lenguaje más directo y vulgar: el amor que siente el poeta se revela devastador, puesto que destruye su corazón que queda reducido a cenizas; mientras que en la segunda el amor inunda sus sentidos, los abrasa pero con una intensidad que se muestra placentera a la vez, reflejada en la paradoja del «suave ardor». Por otro lado, el humo que se desprende del calor del amor en contacto con el helado pecho del amante, se revela cotidiano y paródico en el primero, mientras que en la versión definitiva se sublima en los efectos del amor que inundan el aire y envuelven al amante que no siente sus perjuicios.

Tras esta quinta estancia en la versión de las Flores de poetas ilustres, Lope introduce seis nuevas estrofas a la versión definitiva de la canción para ser publicada en el Burguillos. Se trata de la número 7 a la 12 que abarcan los versos 79 al 156, aportando interesantes elementos literarios. El primero es el desarrollo de la imagen del hombre enamorado a través de la erudición clásica y literaria. Sobre todo recurre a Cupido, se refiere a la obra de Apuleyo, El asno de oro, a los mitos de Adonis, Narciso y Filomena, o a la figura de héroes guerreros como César y Pompeyo. A todos sometió el amor a su capricho. E introduce otro elemento en las dos estancias siguientes relacionado con el primero: la naturaleza como testigo de su desgracia. El poeta se queja de su dolor 
al prado, al monte, al río, en el más puro estilo garcilasiano, y su entorno se conduele de su llanto. Vuelve en la estancia 10 a tratar del amor que igualmente vive sujeto a las leyes morales que libre de sus ataduras, ya que es un sentimiento incontrolable. Y retoma el bucolismo en la siguiente estancia, pero sólo para introducir una escena costumbrista de enorme belleza aunque no exenta de humorismo. Mientras vaga desolado por el prado, se encuentra con su amada Juana que merienda una empanada con su tía Leonor en el soto. Y aunque su pena le consume dice «dejando Amor antojos, / a la empanada me llevó los ojos.». Y es que el amor le entretiene pero no parece mantenerle.

Tras estas estancias viene otra distinta a la sexta de la primera versión, pero con la que tiene ciertas similitudes y sirve también para enlazar con la siguiente, ya igual para ambas versiones. En las Flores esta estrofa pone al poeta ante la causa de su mal, a la que se queja de su lamentable estado, rendido ante el amor no correspondido y hambriento por su culpa (vv. 66-78). Entonces ella le lanza un corazón de pera que se acaba de comer y le dice «Por el tuyo, / este que tengo a mano restituyo.», en un golpe de parodia grotesca, casi cruel. Mientras, en la versión del Burguillos, la estancia 13 muestra al poeta como un perrillo hambriento que suplica en torno a su amada algo de comer, $y$, dice:

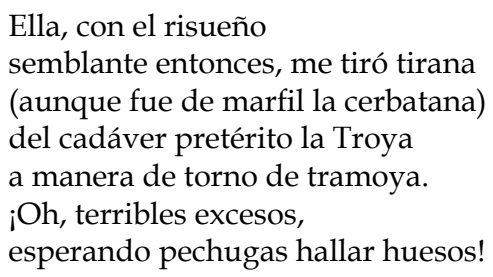

Juana le tira un hueso de capón con su boca. La burla se torna más fuerte que en la primera versión, casi trágica, aunque nunca rompe el tono cómico.

La siguiente estancia, la octava en la versión de las Flores y la quince en la versión del Burguillos, difiere en su totalidad. En ambas se narra la huida de la amada, pero en el primer caso el poeta se vale de una erudición burlesca, identificándose con Alejandro en su firmeza y a ella con Atalanta que huye; mientras que en el segundo caso la furia de Juana es mayor y es expresada por el poeta a través de una metáfora de cetrería apoyada en una fuerte aliteración de los fonemas /r/, /s/ y /m/, que le otorga una viveza y movimiento extraordinario. $\mathrm{Y}$, aunque la estancia termina con un giro burlesco, la huida de Juana por el prado ameno se expresa en bellos términos poéticos. Veamos ambas estancias. A saber, la primera versión:

Al fin se fue la causa por quien muero,

Mas sorda a mis querellas,

Que el golfo, sepultura de Leandro, 
$\mathrm{Y}$ en no se detener la que yo quiero, Mi muerte lamentaran mas donzellas, Que la del hijo del famoso Euandro: Mas yo que de Alexandro Imito el pecho firme quanto puedo, Como pilar de bronze tuue quedo, Y ella como quien corre sobre apuesta, Como Atalanta en el correr dispuesta, $\mathrm{Al}$ viento dio las faldas, Esparciendo turquesas y esmeraldas.

Y la segunda:

Mas habiéndole dicho mi accidente, se levantó furiosa, como suele perdiz que del sonante rocín del cazador la estampa siente, formando aquella rueda sonorosa del vuelo fugitivo retumbante.

El soto, que delante sintió sus caireladas zapatillas, tocaba sus azules campanillas, y al pasar cada flor le daba un beso, en fe de que era el pie cándido queso, aunque en tales rebatos no sé si eran coturnos o zapatos.

Mucho más significativas son las diferencias de la estancia siguiente. Por este lugar por el que el poeta transita su despecho, se encuentra con Venus y su hijo Amor. Para la primera versión:

Y halle entre vnas carrascas

A Venus con su hijo en gran ruydo,

Por escuchar las vozes resistime,

Contra el furor de las mortales bascas,

$\mathrm{Y}$ acomode a las vozes el oydo,

Estaua yo encogido,

Qual se suele poner tierno gazapo,

$Y$ vi que Venus sacudiendo vn trapo,

Limpiaua con sus manos tan hidalgas

De aquel niñon las açotadas nalgas.

En esta primera versión se desarrolla una descripción plástica y directa de una acción muy cotidiana, aunque inusitada en un dios, que se explicita con términos más o menos cargados de crudeza. Comienza con la situación espacial un tanto abrupta, porque las figuras míticas se encuentran entre «unas carrascas», esto es, 'encina pequeña o mata de ella', parece que se están gritando («en gran ruido»), actitud poco educada, califica las manos de la diosa Venus de «hidalgas», humanizándola, y denomina a Cupido «niñón»y se refiere directamente, sin eufemismos, a sus «nalgas». 
La reescritura de estos versos nos deja un poema, que sin modificar su pleno significado, se reviste de una forma bien diferente. Veamos:

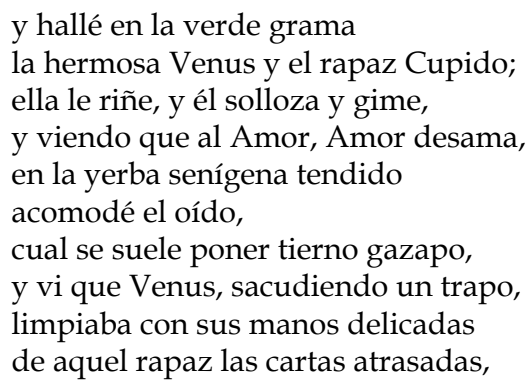

El lugar en el que se encuentran madre e hijo divinos es la «verde grama» que remite a un lugar apacible y ameno, son denominados como «la hermosa Venus y el rapaz Cupido», también con bellos términos y gran musicalidad se describe su discusión materno-filial «ella le riñe y él solloza y gime,». Hasta la actitud del poeta que, sin educación, escucha una conversación ajena, se vuelve ahora más sutil y elevada gracias al cultismo «senígena» ('vieja, la de los campos no roturados') que califica a hierba en la que el poeta acomoda el oído. Además las manos de Venus son ahora «delicadas» y limpia «de aquel rapaz las cartas atrasadas,», empleando términos más apropiados a la divinidad que califican, destacando el empleo del eufemismo concordante con el lenguaje poético.

Sin duda se deconstruye una imagen mítica por la vía de la parodia, pero no la de unos personajes cualquiera sino la de las personificaciones del amor, la belleza y la sensualidad. Todo muy acorde con el sentimiento del yo poético rechazado y humillado por amor.

La segunda versión introduce, a continuación, otra estancia más que incide en este caso y en la que toma la palabra Cupido:

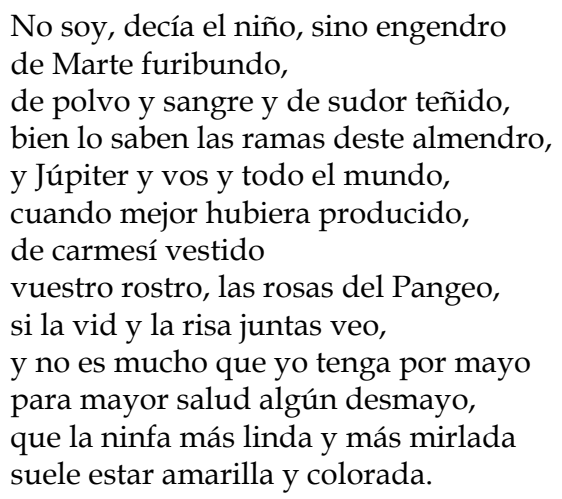

No soy, decía el niño, sino engendro de Marte furibundo, de polvo y sangre y de sudor teñido, bien lo saben las ramas deste almendro, y Júpiter y vos y todo el mundo, cuando mejor hubiera producido, de carmesí vestido vuestro rostro, las rosas del Pangeo, si la vid y la risa juntas veo, y no es mucho que yo tenga por mayo para mayor salud algún desmayo, que la ninfa más linda y más mirlada suele estar amarilla y colorada. 
Se muestra vulnerable como todos los demás, nada extraordinario, idea en la que abunda la estancia que le sigue. En ambas versiones la significación es la misma, pero la expresión resulta bien diferente. Ya desde el inicio en la primera versión el poeta parece reírse de un «boticario», al igual que en la segunda lo hace de un «licenciado» quizás en autorreferencia burlesca a su seudónimo: licenciado Tomé de Burguillos. Veamos la primera:

Reyme entonces yo de vn boticario,

Que en todo su juyzio

Dezia que su dama no hazia

Lo que a nuestra passion es ordinario,

$\mathrm{Y}$ bastome a creerlo aquel indicio,

Viendo que el mismo amor lo padecia.

Ay loca fantasia

De enamorados pechos, no os engañe

El bien que os venga, ni el dolor que os dañe,

Que amor es un cagón lleno de antojos,

Y yo lo he visto por mis propios ojos,

Que en comiendo ciruelas

Se .... en el dolor de vuestras muelas.

Estos versos tan directos y escatológicos, rayanos en lo vulgar, con expresiones como «que su dama no hazia / lo que a nuestra passion es ordinario», siempre referidas a la misma función corporal, como la definición del amor que «es un cagón lleno de antojos», por no mentar el verso final con ese verbo in absentia que todos reconstruimos con suma facilidad.

La reescritura lopesca de estos versos va en la línea del pulido de este tipo de expresiones soeces y demasiado directas para un lenguaje poético que pretende ser culto y elevar el espíritu, si bien también busca claramente la risa o, por lo menos, la sonrisa cómplice con el lector. Así dice la versión del Burguillos:

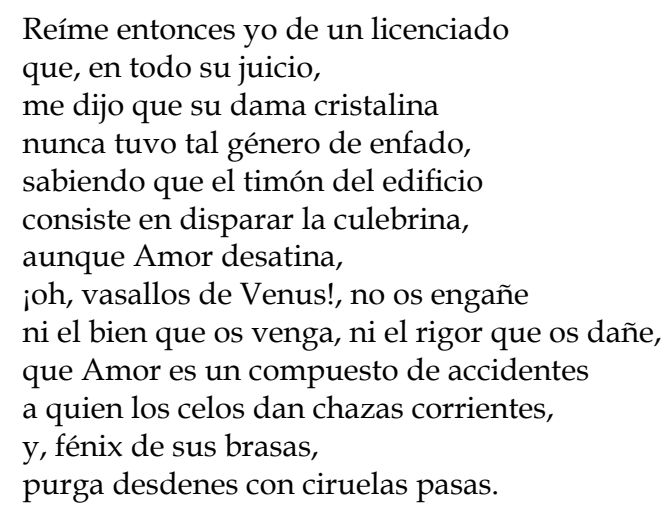

Como se observará sustituye las expresiones anteriores por otras metafóricas y eufemísticas, como «sabiendo que el timón del edificio / consiste en disparar la 
culebrina,", y sin abandonar la idea del niño amor, no lo degrada hasta sus más bajas necesidades fisiológicas, sino que lo califica como «un compuesto de accidentes» que «purga desdenes con ciruelas pasas», en clara referencia, aunque poética, a esta función escatológica. Aún así, su discurso resulta más elaborado por la variable filosófica de los celos indisolublemente unidos al amor, así como la referencia mitológica al ave fénix. Por lo tanto, queda clara en ambas versiones la naturaleza voluble y vulgar del amor que no es más que un niño incontrolado y caprichoso.

La primera versión cierra la canción con los cuatro versos de rigor, mientras que en la segunda, antes de estos, incluye una última estancia más. En ella el poeta se suma al discurso del niño Amor que se declara poco para tanta veneración y atención. En concreto se refiere a la cantidad de poemas dedicados a él que se han hecho en el mundo y que solamente parece que sirven como pañales de su divino trasero.

Lope mantiene en la reescritura de esta canción treinta años después, el tono burlón, paródico y lúdico, incluso irreverente y ridiculizador de la expresión bucólica y la arrebatada pasión amorosa. Pero lo revisa con detalle, reelaborando muchas de sus imágenes, puliendo expresiones, desvulgarizando ideas. Elimina todos los elementos procaces y agresivos buscando un lenguaje poético metafórico, eufemístico, con el que expresa similares significados. Al mismo tiempo desarrolla la parodia del bucolismo y la mitología. En esta línea, las nuevas estancias que introduce se refieren al dios Amor, Cupido, protagonista de una buena parte de la poesía renacentista y barroca. $Y$, por supuesto, este «fénix de sus brasas», ${ }^{9}$ el amor que siempre renace de sí mismo, al que tantas y tantas veces cantó el Lope dramaturgo y poeta, le acompaña hasta su último aliento poético y vital. En este caso, se trata de un amor no correspondido, un niño juguetón y caprichoso.

Estos nuevos versos conseguidos tras la reelaboración de su forma, destilan una mayor madurez literaria, viveza y equilibrio. Se acercan más al ideal de poesía culta que Lope perseguía con avidez, sobre todo en esta etapa final de su vida, el llamado ciclo de senectute. En este caso, Lope adapta la canción al volumen en el que la inserta, las Rimas de Tomé de Burguillos (1634), introduciendo el personaje de Juana, amada e interlocutora de algunos de los sonetos del libro. $\mathrm{Y}$ en este momento, a pesar de su avanzada edad y los desengaños y tragedias sufridos, en Lope continúa intacto su talento innovador que, en este caso, pone al servicio de la reescritura de esta canción.

\footnotetext{
9 Verso 246 de la canción, versión final incluida en las Rimas de Tomé de Burguillos (1634).
} 


\section{APÉNDICE 1}

\section{VERSIONES}

*F Primera versión publicada en la Primera parte de las Flores de poetas ilustres de España (1605) de Pedro de Espinosa (cito por la edición de Inoria Pepe Sarno y José María Reyes Cano para la editorial Cátedra, 2006, pp. 443-447).

Pves que ya de mis versos y passiones todo el mundo presume, y no ay necio que pierda su alcaldada, quiero mudar de estilo y de razones;

5 y pues la misma pena me consume, tomar la lyra menos bien templada. ¡Ó vos, rubia manada, y todas las demás, que passo a passo pazéys los alcaceles del Parnaso!

10 Prestáme vuestra ayuda o melecina, para que el vulgachón que me adeuina no entienda los concetos que entre vuestras albardas van secretos.

Que si escriuiendo en socarrón estilo,

15 segunda vez pretende hazer glossa a mis versos, desde agora, de los que habitan el egipcio Nilo a los que en la Etiopía el sol enciende, en los bordados reynos del aurora,

20 donde el árabe mora, aprenderé la lengua no entendida, dexando escura fama en larga vida; mas yo fío, Piéredes, que en tanto afloxaréys las cinchas a mi canto,

25 y que en este lenguaje, Leteo me dará franco passage.

Riberas del estrecho Mançanares, por donde antiguamente alborotó los límites postreros,

30 la que tuuo a Ionás en los hijares, haziendo turbia la raudal corriente de paja y vino del albarda y cueros, a fuerça de los fieros chuzos y dardos de la gente armada,

35 que por la puente le estoruó la entrada, vn soto lleno de verdura y caça, donde prueuan los toros de la plaça, cubre la orilla amena, de chopos, lirios, sauces y verbena.

40 En éste, vn martes pardo, haziago y malo, para bodas y telas, entre la grama y los menudos juncos vi vn sol, a cuya vista me regalo, aquellos ojos como dos candelas, 
45 y es poco si dixera dos carbuncos.

No desde los aruncos

a nuestros montañeses vieron dama

tan bella, los antojos de la fama.

$\mathrm{Al}$ fin yo vi su rostro de manteca,

50 que en sólo vella el pensamiento peca,

y luego a mi derecha

mase Cupido disparó vna flecha,

No suele el sol tan libre y licencioso,

entrar por los resquicios

55 de los zaquizamíes de teja vana,

como entró, por matarme, poderoso

aquel diuino sol, cuyos solsticios

hicieron d'esta vez mi alma vfana;

entró por la ventana

60 de aquestos ojos a mi elado pecho,

que allí me lo dexó ceniza hecho,

tanto, que el humo espeso que salía,

de horno de ladrillo parecía:

si alguno me encontraua,

65 del tufo de mi mal estornudaua.

Boluíme a ver la causa de mi muerte,

$\mathrm{y}$ en quien esta mi vida,

y con toda esta cara de puchero

le dixe de la suerte que mi suerte

70 mi pura voluntad dexó rendida

al yugo del amor sabroso y fiero,

y mostréle el garguero,

traspassado de hambre a causa suya;

y ella, por darme vn poco de alleluya,

75 me tiró con la mano que tenía

vn coraçon de pena que comía,

diziendo: "Por el tuyo,

este que tengo a mano restituyo.".

Dióme en la nuez el golpe, que me hizo

80 sacar toda la lengua,

como perro con huesso atrauessado,

mas luego con el gusto se deshizo,

que no se ha de tener a mucha mengua

por vn fauor salir descalabrado.

85 Sentíme consolado

del golpe, que, en señal de mi vitoria,

sonó como quien muerde zanahoria,

más apazible que al villano oýdo

el dulce son del rábano partido;

90 y como dio en lo hueco,

abaxo respondió la ninfa Eco.

Al fin se fue la causa por quien muero,

más sorda a mis querellas

que el golfo sepultura de Leandro;

95 y en no se detener la que yo quiero,

mi muerte lamentaran más doncellas

que la del hijo del famoso Evandro. 
Mas yo, que de Alexandro

imito el pecho firme quanto puedo,

100 como pilar de bronze tuue quedo;

y ella, como quien corre sobre apuesta,

como Atalanta en el correr dispuesta,

al viento dio las faldas,

esparciendo turquesas y esmeraldas.

105 No suele algún sardesco de mañana, de su chozuela pobre

salir brioso dando mil carreras, repicando a su son de buena gana

los abollados cántaros de cobre,

110 entre las sonadoras aguaderas,

ni fueron tan ligeras

de Dafne las castizas cosetadas,

como de mi enemiga las pisadas

y aquel donoso y zahareño brío,

115 que allá se lleua el pensamiento mío,

dexando a mi alma sola,

como Progne vna pluma de su cola.

Yo despechado por las seluas fuýme,

y hallé entre vnas carrascas

120 a Venus con su hijo en gran rüydo;

por escuchar las vozes resistíme

contra el furor de las mortales bascas,

y acomodé a las vozes el oýdo.

Estaua yo encogido,

125 qual se suele poner tierno gazapo,

y vi que Venus sacudiendo vn trapo,

limpiaua con sus manos tan hidalgas

de aquel niñon las açotadas nalgas.

$\mathrm{y}$ triste en ser su madre,

130 maldezía al herrero de su padre.

Reýme entonces yo de vn boticario

que, en todo su juÿzio,

dezía que su dama no hazía

lo que a nuestra passión es ordinario;

135 y bastóme a creerlo aquel indicio, viendo que el mismo Amor lo padecía.

¡Ay loca fantasía

de enamorados pechos! No os engañe

el bien que os venga, ni el dolor que os dañe:

140 que Amor es un cagón lleno de antojos;

y yo lo he visto por mis propios ojos,

que en comiendo ciruelas,

se .... en el dolor de vuestras muelas.

Canción, si acaso vas a passearte

145 al prado o a otra parte,

pássate por en cas de vn alojero,

$\mathrm{y}$ dile que me muero. 
Segunda versión publicada en las Rimas humanas y divinas del licenciado Tomé de Burguillos (1634) (cito por la edición de Macarena Cuiñas Gómez, Madrid: Cátedra, 2008, pp. 427-438).

$$
\text { MURMURABAN AL POETA }
$$

la parte donde amaba por los versos que

hacía

\section{CANCIÓN}

Ya pues que todo el mundo mis pasiones de mis versos presume, culpa de mis hipérboles causada, quiero mudar de estilo y de razones $\mathrm{y}$, pues la misma pena me consume, tomar la lira menos bien templada. ¡Oh vos, rubia manada!, y todos los demás que paso a paso pacéis los alcaceres del Parnaso,

10 prestadme vuestra ayuda sobre prenda para que el vulgo bárbaro no entienda por mis necios efectos el alma de mis versos y concetos.

Que si animando tan humilde estilo,

15 segunda vez pretende comentar mis desdichas desde agora, de los que habitan el egipcio Nilo o los que en Etiopia el Sol enciende, y en los bordados reinos del Aurora,

20 que Febo infante dora, aprenderé la lengua no entendida, dejando escura fama en larga vida. Mas yo fío, Piérides, que en tanto aflojaréis las cinchas a mi canto,

25 y que en este lenguaje el Lete me dará franco pasaje.

Riberas del estrecho Manzanares, (por donde antiguamente alborotó sus límites postreros

30 la que tuvo a Jonás en los ijares, escureciendo su cristal corriente la paja y vino del albarda y cueros a fuerza de los fieros dardos y chuzos de la gente armada,

35 que por la puente le estorbó la entrada), un soto lleno de verdura y caza, donde prueban los toros de la plaza, cubre la orilla amena de chopos, sauces, lirios y verbena.

40 En éste, un martes pardo, aciago y malo para casar doncellas, entre la grama y los menudos juncos 
vi el sol, a cuya vista me regalo, y aquellos ojos como dos estrellas,

45 y es poco si dijera dos carbuncos.

No desde los aruncos

a nuestros montañeses vieron dama

tan bella los antojos de la fama.

Al fin yo vi su rostro y su aguileña

50 nariz como remate de cermeña,

y aquella boca hermosa,

que dejó de ser guinda por ser rosa.

Mas si Cupido, entonces lisonjero,

en vez de la sangrienta

55 ballesta de sangrar rocines y hacas,

tiróme con la mano de un mortero,

que, durmiendo una noche en una venta,

hurtó para tirar a las urracas;

tal en indias hamacas

60 suele desvanecerse, o en la nave,

quien ni del mar ni del columpio sabe,

quedando yo tan triste y descompuesto

como después de las vendimias cesto,

dando más estornudos

65 que los tabacos dan por los embudos.

No suele el sol más libre y licencioso

entrar por un resquicio

en un zaquizamí de teja vana,

que el rayo ilustre de su rostro hermoso.

70 Haciendo en mí piramidal solsticio

con dulce fuerza de opresión tirana,

entró por la ventana

de aquestos ojos a mi helado pecho,

suave ardor de mis sentidos hecho,

75 aunque el fuego que el humo interrumpía

en densa nube el aire convertía.

$\mathrm{Si}$ alguno me miraba

del tufo de mi mal estornudaba.

Rapaz Amor, ¿qué es esto?, ¿quién te ha dado

80 fuerza tan poderosa

desde la roja púrpura al plebeyo

sayal que sigue el buey con el arado?,

¿qué Pangeo produce aquella rosa,

Astolfo del sentido de Apuleyo?,

85 ¿qué César, qué Pompeyo,

qué pastor, qué rocín rucio o castaño

no hirió tu flecha, ni rindió tu engaño?,

¿qué Adonis, qué Narciso o Filomena

en flor o en pluma no lloró tu pena?

90 Todos mueren de amores:

César, rocín, pastor, aves y flores.

Allí con los ardores del veneno,

aunque dulce contrario,

a la quietud del corazón rendido,

95 quejéme al soto, al prado, al campo ameno 
de aquel mortal arquero Sagitario, desnudo de temor, de error vestido.

El río, condolido

de lástima, corrió como solía,

100 y las aves con dulce melodía

animaban los céfiros suaves,

que también en las flores eran aves,

y patos y conejos

escuchaban mis penas desde lejos.

105 Álamo no quedó, no quedó fuente,

pastor ni lavandera,

novillo en soto ni borrico en prado,

que no se condoliese tiernamente

de ver en su ribera

110 llorar de amor un hombre licenciado,

tan docto y tan barbado,

como si el alma fuese vieja o niña,

barbada por los lados o lampiña,

ni es centro el cuerpo del amor heroico,

115 aunque no soy platónico ni estoico,

siguiendo en esta tema

aquel aristotélico teorema.

Dijo este tal autor, que en griego escribe

por no ser de la Mancha

120 y ser la lengua en que nacido había,

que amor en conjugales lazos vive,

y sin ellos también, que tanto ensancha

de su juridición la monarquía,

que fue sentencia fría,

125 aunque la diga el rey filosofante,

no porque la condeno repugnante,

pero siendo juez naturaleza,

amable, por ser bien, es la belleza,

y sin comunicarse

130 pudiera de Aristóteles quejarse.

Viéndome, en fin, que por las selvas solas

sátiro parecía,

amante sin dinero, pobre y roto,

envidiaba las cándidas tortolas,

135 aunque mayor envidia me afligía

de los que merendaban en el soto.

Mas cuando más remoto

de todo bien sin esperanza estaba,

vi que la bella Juana merendaba

140 una empanada con Leonor, su tía,

y aunque era el alba de quien sale el día,

dejando Amor antojos,

a la empanada me llevó los ojos.

Si con hambre no hay Venus que aproveche,

145 tanta descortesía

disculpe, si de Amor fuere culpada,

en pan de azúcar un capón de leche,

y aunque Juana tan linda parecía, 
de más sazón estaba la empanada,

150 invención regalada,

y más que para oír tiples eunucos,

si merendaran habas o almendrucos,

pudiérase quejar de mi deseo,

pero entre cuantos platos dulces veo,

155 puede comer el Fúcar

tiple de teta en círculos de azúcar.

No de otra suerte gozque hambriento esgrime

blanda flexible cola

en torno de la mesa de su dueño,

$160 \mathrm{y}$ con lengua anhelante gruñe y gime,

ya con ladrido y ya con cabriola,

que yo con muda queja el alma enseño.

Ella, con el risueño

semblante entonces, me tiró tirana

165 (aunque fue de marfil la cerbatana)

del cadáver pretérito la Troya

a manera de torno de tramoya.

¡Oh, terribles excesos,

170 Diome en la nuez el golpe que me hizo

sacar toda la lengua,

como perro con hueso atravesado;

mas el favor la pena satisfizo,

que no es amando mengua

175 salir favorecido y agraviado.

Sentíme consolado

del golpe, que, en señal de mi vitoria,

sonó como quien muerde zanahoria,

más apacible que al villano oído

180 el dulce son del rábano partido;

y como hirió en lo hueco,

opuesta resonó la ninfa Eco.

Mas habiéndole dicho mi accidente,

se levantó furiosa,

185 como suele perdiz que del sonante

rocín del cazador la estampa siente,

formando aquella rueda sonorosa

del vuelo fugitivo retumbante.

El soto, que delante

190 sintió sus caireladas zapatillas, tocaba sus azules campanillas,

y al pasar cada flor le daba un beso, en fe de que era el pie cándido queso, aunque en tales rebatos

195 no sé si eran coturnos o zapatos.

No suele algún sardesco, de mañana, de su chozuela pobre

salir brioso dando mil carreras, repicando a su son, como campana,

200 los abollados cántaros de cobre entre las sonadoras aguaderas, 
ni fueron tan ligeras

de Dafne las castizas cosetadas, como de mi enemiga las pisadas,

205 y aquel brioso zahareño brío, que allá se lleva el pensamiento mío, dejando a mi deseo la pluma que dejó Progne a Tereo. Yo, despechado, por la selva fuime,

210 y hallé en la verde grama la hermosa Venus y el rapaz Cupido; ella le riñe, y él solloza y gime, y viendo que al Amor, Amor desama, en la yerba senígena tendido

215 acomodé el oído, cual se suele poner tierno gazapo, y vi que Venus, sacudiendo un trapo, limpiaba con sus manos delicadas de aquel rapaz las cartas atrasadas,

220 y triste en ser su madre maldecía el herrero de su padre.

"No soy, decía el niño, sino engendro de Marte furibundo, de polvo y sangre y de sudor teñido,

225 bien lo saben las ramas deste almendro, y Júpiter y vos y todo el mundo, cuando mejor hubiera producido, de carmesí vestido vuestro rostro, las rosas del Pangeo,

230 si la vid y la risa juntas veo, y no es mucho que yo tenga por mayo para mayor salud algún desmayo, que la ninfa más linda y más mirlada suele estar amarilla y colorada."

235 Reíme entonces yo de un licenciado que, en todo su juicio, me dijo que su dama cristalina nunca tuvo tal género de enfado, sabiendo que el timón del edificio

240 consiste en disparar la culebrina, aunque Amor desatina, ¡oh, vasallos de Venus!, no os engañe ni el bien que os venga, ni el rigor que os dañe, que Amor es un compuesto de accidentes

245 a quien los celos dan chazas corrientes, $y$, fénix de sus brasas, purga desdenes con ciruelas pasas.

Amor tuvo razón, y yo lo fundo en que, por no ser tales,

250 para pañales del señor Cupido se hicieron muchos versos en el mundo, que, como de otros lienzos principales, los poetas tal vez los han rompido, y es cosa que ha venido 
255 a ser fragmento inútil a su dueño; cuando Venus al niño rinde al sueño, quitando el borrador, pone el traslado, aunque todo después queda borrado. ¡Dichoso aquel conceto

260 que se pudo librar de tanto aprieto! Canción, si acaso vas a pasearte al Prado o a otra parte, pásate por en cas de un alojero y dile cómo muero.

\section{APÉNDICE 2}

\section{VARIANTES}

En este apartado establezco un listado de las variantes que observo entre las dos versiones de la Canción que he analizado en el presente trabajo. Para una mejor comprensión he asignado iniciales a cada versión.

CANCIÓN de las Rimas de Tomé de Burguillos titulada «Murmuraban al poeta la parte donde amaba por los versos que hacía». La primera versión es $\boldsymbol{F}$ por haber sido publicada en la Primera parte de las Flores de poetas ilustres de España (1605) de Pedro de Espinosa ${ }^{10}$, y la definitiva $\boldsymbol{B}$ por formar parte de las Rimas humanas y divinas del licenciado Tomé de Burguillos (1634). ${ }^{11}$

F vv. 1-3 «Pves que ya de mis versos y passiones / todo el mundo presume, / y no ay necio que pierda su alcaldada,»

y $\boldsymbol{B}$ vv. 1-3 «Ya pues que todo el mundo mis pasiones / de mis versos presume, / culpa de mis hipérboles causada,».

F v. 8 «todas las»y $B$ v. 8 «todos los».

$\boldsymbol{F}$ v. 9 «alcaceles» y $\boldsymbol{B}$ v. 9 «alcaceres».

F v. 10 «Prestame» «o melecina» y B v. 10 «prestadme» «sobre prenda».

F v. 11 «el vulgachón que me adevina» y $\boldsymbol{B}$ v. 11 «el vulgo bárbaro no entienda».

${ }_{10}$ Cito por la edición de las Flores de Inoria Pepe Sarno y José María Reyes Cano, Madrid: Cátedra, 2006, pp. 443-448.

11 Cito por la edición del Burguillos de Macarena Cuiñas Gómez, Madrid: Cátedra, 2008, pp. 427-438. 


\section{Macarena Cuiñas Gómez}

$\boldsymbol{F}$ vv. 12-13 «no entienda los concetos / que entre vuestras albardas van secretos.» y $\boldsymbol{B}$ vv. 12-13 «por mis necios efectos / el alma de mis verso y concetos.».

F v. 14 «escribiendo en socarrón estilo» y B v. 14 «animando tan humilde estilo,».

$\boldsymbol{F}$ v. 16 «hazer glossa a mis versos,» y $\boldsymbol{B}$ v. 16 «comentar mis desdichas».

$\boldsymbol{F}$ v. 18 «a» y $\boldsymbol{B}$ v. 18 «»».

B v. 19 «y».

$\boldsymbol{F}$ v. 20 «donde el árabe mora,» y $\boldsymbol{B}$ v. 20 «que Febo infante dora».

$\boldsymbol{F}$ v. 26 «Leteo» y $\boldsymbol{B}$ v. 26 «el Lete».

$\boldsymbol{F}$ v. 29 «los» y B v. 29 «us».

$\boldsymbol{F}$ v.31 «haziendo turbia la raudal corriente» y $\boldsymbol{B}$ v. 31 «escureciendo su cristal corriente».

$\boldsymbol{F}$ v. 32 «de» y $\boldsymbol{B}$ v. 32 «la».

F v. 34 «chuzos y dardos» y $\boldsymbol{B}$ v. 34 «dardos y chuzos».

F v. 39 «lirios, sauces» y B v. 39 «sauces, lirios».

$\boldsymbol{F}$ v. 41 «bodas y telas» y $\boldsymbol{B}$ v. 41 «casar doncellas».

$\boldsymbol{F}$ v. 43 «un»y $\boldsymbol{B}$ v. 43 «el».

F v. 44 «candelas»y B v. 44 «y» «estrellas».

$\boldsymbol{F}$ v. 49 «de manteca» y $\boldsymbol{B}$ v. 49 «y su aguileña».

$\boldsymbol{F}$ vv. 50-52 «que en sólo vella el pensamiento peca, / y luego a mi derecha / mase Cupido disparó una flecha.» y $\boldsymbol{B}$ vv. 50-52 «nariz como remate de cermeña, / y aquella boca hermosa, / que dejó de ser guinda por ser rosa.».

B introduce una nueva estancia: vv. 53-65.

$F$ v. 53 «tan» y $B$ v. 66 «más».

$\boldsymbol{F}$ v. 54 «los resquicios» y $\boldsymbol{B}$ v. 67 «un resquicio».

$\boldsymbol{F}$ v. 55 «de los zaquizamíes» y $\boldsymbol{B}$ v. 68 «en un zaquizamí». 
$F$ vv. 56-58 «como entró, por matarme poderoso / aquel divino sol, cuyos solsticios / hicieron d' esta vez mi alma ufana;» y $\boldsymbol{B}$ vv. 69-71 «que el rayo ilustre de su rostro hermoso. / Haciendo en mí piramidal solsticios / con dulce fuerza de opresión tirana».

F vv. 61-63 «que allí me lo dexó ceniza hecho, / tanto, que el humo espeso que salía, / de horno de ladrillo parecía:» y $\boldsymbol{B}$ vv. 74-76 «suave ardor de mis sentidos hecho, / aunque el fuego que el humo interrumpía / en densa nube el aire convertía.».

$\boldsymbol{F}$ v. 64 «encontraua»y $\boldsymbol{B}$ v. 77 «miraba».

B introduce seis nuevas estancias: vv. 79-156.

$\boldsymbol{F}$ vv. 66-78 una estancia distinta de $\boldsymbol{B}$ vv. 157-169.

$F$ vv. 82-84 «mas luego con el gusto se deshizo: / que no se ha de tener a mucha mengua / por vn favor salir descalabrado.» Y $\boldsymbol{B}$ vv. 173-175 «mas el favor la pena satisfizo, / que no es amando mengua / salir favorecido y agraviado.».

$\boldsymbol{F}$ v. 90 «dio»y $\boldsymbol{B}$ v. 181 «hirió».

F v. 91 «abaxo respondió» y $\boldsymbol{B}$ v. 182 «opuesta resonó».

$\boldsymbol{F}$ vv. 92-104 una estancia distinta de $\boldsymbol{B}$ vv. 183-195.

F v. 108 «de buena gana» y B v. 199 «como campana».

F v. 114 «donoso y» y B v. 205 «brioso».

$\boldsymbol{F}$ v. 116 «alma sola»y $\boldsymbol{B}$ v. 207 «deseo».

F 117 «como Progne, vna pluma de su cola.» y B v. 208 «la pluma que dejó Progne a Tereo.».

F v. 118 «las seluas» y B v. 209 «la selva».

$\boldsymbol{F}$ v. 119 «entre vnas carrascas» y $\boldsymbol{B}$ v. 210 «en la verde grama».

F vv. 120-124 «a Venus con su hijo en gran rüydo; / por escuchar las vozes resistíme / contra el furor de las mortales bascas, / y acomodé a las vozes el oýdo, / Estaua yo encogido,» y $\boldsymbol{B}$ vv. 211-215 «la hemosa Venus y el rapaz Cupido; / ella le riñe, y él solloza y gime, / y viendo que al Amor, Amor desama, / en la yerba senígena tendido / acomodé el oído,».

$\boldsymbol{F}$ v. 127 «tan hidalgas» y B v. 218 «delicadas». 
$\boldsymbol{F}$ v. 128 «de aquel riñón las açotadas nalgas» y $\boldsymbol{B}$ v. 219 «de aquel rapaz las cartas atrasadas».

B introduce una nueva estancia: vv. 222-234.

F v. 131 «boticario» y $\boldsymbol{B}$ «licenciado».

F vv. 133-137 «dezía que su dama no hazía / lo que a nuestra passión es ordinario; / y bastóme a creerlo aquel indicio, / viendo que el mismo Amor lo padecía. » Y B vv. 237241 «me dijo que su dama cristalina / nunca tuvo tal género de enfado, / sabiendo que el timón del edificio / consiste en disparar la culebrina, / aunque Amor desatina,».

F v. 138 «de enamorados pechos!» y B v. 242 «oh, vasallos de Venus!».

$\boldsymbol{F}$ v. 139 «el bien» «dolor» y B v. 243 «ni el bien» «rigor».

F v. 140 «cagón lleno de antojos» y B v. 244 «compuesto de accidentes».

$F$ vv. 141-143 «y yo lo he visto por mis propios ojos, / que en comiendo ciruelas, / se ... en el dolor de vuestras muelas.» Y $B$ vv. 245-247 «a quien los celos dan chazas corrientes, / y, fénix de sus brasas, / purga desdenes con ciruelas pasas.».

$B$ introduce una nueva estancia: vv. 248-260.

F v. 147 «que me» y B v. 264 «cómo». 